\title{
Baicalin inhibits C2C12 myoblast apoptosis and prevents against skeletal muscle injury
}

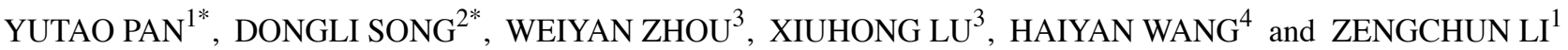 \\ ${ }^{1}$ Department of Emergency and Trauma Surgery, Shanghai East Hospital, Tongji University School of Medicine, \\ Shanghai 200120; ${ }^{2}$ Zhongshan Hospital Clinical Science Institute, Fudan University, Shanghai 200032; \\ ${ }^{3}$ PET Center, Huashan Hospital, Fudan University, Shanghai 200235; ${ }^{4}$ Department of Nuclear Medicine, \\ Shanghai East Hospital, Tongji University School of Medicine, Shanghai 200120, P.R. China
}

Received October 7, 2018; Accepted April 30, 2019

DOI: $10.3892 / \mathrm{mmr} .2019 .10298$

\begin{abstract}
Anti-apoptotic and anti-inflammatory treatments are imperative for skeletal muscle regeneration following injury. Baicalin is well known and has previously been investigated for its role in the treatment of injury and inflammatory diseases. Therefore, the present study aimed to investigate the effects of baicalin in inhibiting apoptosis of $\mathrm{C} 2 \mathrm{C} 12$ myoblasts and preventing skeletal muscle injury. A cell counting kit-8 (CCK-8) assay and Annexin V/PI staining were initially performed to measure cell viability and apoptosis under conditions of $\mathrm{H}_{2} \mathrm{O}_{2}$ exposure with or without baicalin. Subsequently, oxidative activity, mitochondrial function, mitochondrial apoptogenic factors and caspase proteins were analyzed to examine the mechanism underlying the effect of baicalin on inhibiting apoptosis in $\mathrm{C} 2 \mathrm{C} 12$ myoblasts. Furthermore, $\mathrm{BALB} / \mathrm{C}$ mice with skeletal muscle injuries were established, and the potential application of baicalin for anti-apoptotic and anti-inflammatory effects was examined via small animal $\beta-2$ [18F]-fluoro-2-deoxy-D-glucose $\left({ }^{18} \mathrm{~F}\right.$-FDG) positron emission tomography (PET) imaging and pathological examination. The CCK-8 assay and Annexin V/PI staining revealed cell death in the $\mathrm{C} 2 \mathrm{C} 12$ myoblasts induced by $\mathrm{H}_{2} \mathrm{O}_{2}$, which was apoptotic, and this was effectively reversed by treatment with baicalin. $\mathrm{H}_{2} \mathrm{O}_{2}$ increased the reactive oxygen species and malondialdehyde levels in $\mathrm{C} 2 \mathrm{C} 12$ myoblasts, which was caused by mitochondrial dysfunction, decreased expression of cytochrome $c$ and apoptosis-inducing factor from cytosolic and mitochondrial fractions, and activated expression of caspase-3
\end{abstract}

Correspondence to: Dr Zengchun Li, Department of Emergency and Trauma Surgery, Shanghai East Hospital, Tongji University School of Medicine, 150 Jimo Road, Shanghai 200120, P.R. China E-mail:1zc0155@easthospital.cn

"Contributed equally

Key words: baicalin, $\mathrm{C} 2 \mathrm{C} 12$ myoblasts, apoptosis, injured skeletal muscle, $\beta-2-[18 \mathrm{~F}]$-fluoro-2-deoxy-D-glucose, positron emission tomography and caspase-9; however, treatment with baicalin reversed these effects. In addition, small animal PET imaging revealed that treatment with baicalin decreased the accumulation of FDG by $\sim 65.9 \%$ in the injured skeletal muscle induced by $\mathrm{H}_{2} \mathrm{O}_{2}$. These pathological results also confirmed the protective effect of baicalin on injured skeletal muscle. Taken together, the results of the present study indicated that baicalin effectively inhibited the apoptosis of $\mathrm{C} 2 \mathrm{C} 12$ myoblasts and protected skeletal muscle from injury, which may have potential therapeutic benefits for patients in a clinical setting.

\section{Introduction}

Exercise, eccentric contractions, acute trauma and disease are all causal mechanisms of skeletal muscle injury (1-5). Although the type of injury differs, the general injury and repair mechanisms are similar (1-5). When skeletal muscle is injured, it undergoes sequential phases of degeneration, inflammation, regeneration and fibrosis (1-5). For the repair and regeneration of skeletal muscle, it is important to induce the proliferation and differentiation of skeletal myoblasts and to inhibit the apoptosis of myoblasts (2). Therefore, anti-inflammatory and anti-apoptotic treatments are important for skeletal muscle regeneration and to promote healing following the occurrence of injury $(1,4-6)$.

Baicalin is a flavonoid glycoside extracted from Scutellaria baicalensis, which is used in traditional Chinese medicine, has been reported to possess significant anti-inflammatory and anti-apoptotic properties, and is widely used in the treatment of injury and inflammatory diseases (7-12). For example, Lin et al $(7,8)$ reported that baicalin inhibited $\mathrm{H}_{2} \mathrm{O}_{2}$-induced cell cytotoxicity in a human renal proximal tubular epithelial cell line, and attenuated renal ischemia-reperfusion injury by suppressing inflammation and apoptosis. A study by Cao et al (9) demonstrated that baicalin attenuated global cerebral ischemia/reperfusion injury in gerbils through anti-oxidative and anti-apoptotic pathways. In addition, Zhu et al (10) reported that baicalin increased survival in a murine model of polymicrobial sepsis through inhibiting the inflammatory response and lymphocyte apoptosis, and Xiping et al (11) demonstrated that baicalin offered protection to the thymus rats with severe acute pancreatitis. Our 
previous study also demonstrated that baicalin significantly inhibited oxidative stress damage induced by $\mathrm{H}_{2} \mathrm{O}_{2}$ and decreased cell apoptosis in endplate chondrocytes, which may provide potential therapeutic benefits for patients with osteoarthritis (13).

Therefore, in order to further investigate the underlying role and mechanism of baicalin in injured skeletal muscle, the present study focused on $\mathrm{H}_{2} \mathrm{O}_{2}$-stimulated $\mathrm{C} 2 \mathrm{C} 12$ myoblasts in vitro to investigate the role of baicalin on cell apoptosis, and established an animal model of injured skeletal muscle to observe the influence of baicalin on the uptake of $\beta-2-[18 \mathrm{~F}]-\mathrm{fl}$ uoro-2-deoxy-D-glucose $\left({ }^{18} \mathrm{~F}-\mathrm{FDG}\right)$ in lesions in vivo via small animal positron emission tomography (PET) imaging.

\section{Materials and methods}

Cell viability. C2C12 mouse myoblast cells (ATCC, cat. no. CRL-1772) were grown in 96-well plates (BD Falcon; BD Biosciences, San Jose, CA, USA) at a density of $\sim 1 \times 10 \%$ ml $(100 \mu \mathrm{l} /$ well $)$ in Dulbecco's modified Eagle's medium (DMEM; Gibco; Thermo Fisher Scientific, Inc.), supplemented with $10 \%$ fetal bovine serum (FBS; Gibco; Thermo Fisher Scientific, Inc.), $100 \mathrm{U} / \mathrm{ml}$ penicillin and streptomycin (Gibco; Thermo Fisher Scientific, Inc.). The C2C12 myoblasts were then washed with PBS buffer (Gibco; Thermo Fisher Scientific, Inc.) and incubated with medium containing different concentrations of $\mathrm{H}_{2} \mathrm{O}_{2}(0,50,100,150,200,300$, 500, 600, 800 and 1,000 $\mu \mathrm{M}$; Lingfeng, Shanghai, China) at $37^{\circ} \mathrm{C}$ for $4 \mathrm{~h}$, respectively. Untreated cells were referred to as the normal control. The cell viability of $\mathrm{C} 2 \mathrm{C} 12$ myoblasts was determined using a cell counting kit-8 (CCK-8) assay (Dojindo Molecular Technologies, Inc., Kumamoto, Japan). The C2C12 myoblasts were subsequently incubated with $\mathrm{H}_{2} \mathrm{O}_{2}(500 \mu \mathrm{M})$ under the co-existence of baicalin at various treatment time points $(-1,0,1$ and $2 \mathrm{~h})$ at $37^{\circ} \mathrm{C}$ for $4 \mathrm{~h}$, respectively. In addition, to judge the optimal incubation time, the appropriate treated concentration of baicalin on $\mathrm{C} 2 \mathrm{C} 12$ myoblasts was also investigated. The $\mathrm{C} 2 \mathrm{C} 12$ myoblasts were pretreated with baicalin at different concentrations $(5,15,25$, $50,100,150,200,250$ and $300 \mu \mathrm{M})$ for $1 \mathrm{~h}$, and were then incubated with $\mathrm{H}_{2} \mathrm{O}_{2}(500 \mu \mathrm{M})$ at $37^{\circ} \mathrm{C}$ for $4 \mathrm{~h}$, respectively. Untreated cells and cells treated with $\mathrm{H}_{2} \mathrm{O}_{2}$ only were referred to as the control groups. Cell viability was determined using a 1:10 dilution of CCK-8 reagent and incubated at $37^{\circ} \mathrm{C}$ for $1 \mathrm{~h}$. All the above data are presented as the mean of at least three independent experimental repeats.

Cell apoptosis. The apoptosis of $\mathrm{C} 2 \mathrm{C} 12$ myoblasts incubated in the three groups (treated with $500 \mu \mathrm{M} \mathrm{H}_{2} \mathrm{O}_{2}$, treated with $500 \mu \mathrm{M} \mathrm{H}_{2} \mathrm{O}_{2}+100 \mu \mathrm{M}$ baicalin pre-treatment for $1 \mathrm{~h}$, and the normal control) for $4 \mathrm{~h}$ was measured using an Annexin V/PI assay kit (Nanjing KeyGen Biotech Co., Ltd., Nanjing, China) for flow cytometric analysis. Briefly, the cells from each group were washed with PBS three times, harvested with $0.25 \%$ trypsin and centrifuged at $400 \mathrm{x}$ g for $5 \mathrm{~min}$ at room temperature. The supernatant was discarded, cells were resuspended in $500 \mu \mathrm{l}$ binding buffer and then immediately mixed with $5 \mu \mathrm{l}$ Annexin V-FITC and $5 \mu \mathrm{l}$ propidium iodide and incubated for 10-15 $\mathrm{min}$ at room temperature. Finally, the mixture was analyzed using a BD FACS Aria II flow cytometry
(BD Biosciences). All data are presented as the mean of at least three independent experimental repeats.

Oxidative activity. The oxidative activity was assessed in the three aforementioned groups following incubation with $\mathrm{H}_{2} \mathrm{O}_{2}$ for $4 \mathrm{~h}$. Following treatment, cells from each of the groups were washed with PBS three times, harvested with $0.25 \%$ trypsin and centrifuged at $400 \mathrm{x}$ g for $5 \mathrm{~min}$ at room temperature. The supernatant was discarded, and the cells were incubated with ROS working fluid (cat. no. KGT010-1; Nanjing KeyGen Biotech Co., Ltd.) at $37^{\circ} \mathrm{C}$ for $15 \mathrm{~min}$. The ROS working fluid was then removed, fresh PBS was added, and detection was performed with BD FACS Aria II flow cytometry (BD Biosciences) with an excitation wavelength of $488 \mathrm{~nm}$, an emission wavelength of $525 \mathrm{~nm}$ and the channel of fluorescein isothiocyanate (FITC). Finally, the results of flow cytometry were analyzed using Flowjo 10.1 software (Flowjo, LLC, Ashland, OR, USA). All the above data are presented as the mean of at least three independent experimental repeats.

In addition, the cells from each group were washed with cold PBS three times, harvested with $0.25 \%$ trypsin, and centrifuged at $400 \mathrm{x} \mathrm{g}$ for $5 \mathrm{~min}$ at room temperature. The supernatant was discarded, and the cells were lysed with radio immunoprecipitation assay (RIPA) buffer and centrifuged at $12,000 \mathrm{~g}$ for $10 \mathrm{~min}$ at $4^{\circ} \mathrm{C}$. Following this, $100 \mu \mathrm{l}$ supernatant and $200 \mu 1$ malondialdehyde (MDA) working solution (cat. no. KGT003; Nanjing KeyGen Biotech Co., Ltd.) were mixed and added to the 96-well plate. The absorbance of each well was then measured at a wavelength of $532 \mathrm{~nm}$ in an enzyme-linked immunometric meter (FlexStation 3; Molecular Devices, LLC, Sunnyvale, CA, USA). All the above data are presented as the mean of at least three independent experimental repeats.

Mitochondrial function. Rhodamine 123 (cat. no. KGA217; Nanjing KeyGen Biotech Co., Ltd.) were analyzed in above three groups following the incubation with $\mathrm{H}_{2} \mathrm{O}_{2}$ for $4 \mathrm{~h}$. Following treatment, cells from each group were washed with PBS three times, harvested with $0.25 \%$ trypsin, and centrifuged at $400 \mathrm{x} \mathrm{g}$ for $5 \mathrm{~min}$ at room temperature. The supernatant was discarded, and the cells was incubated with Rhodamine 123 working fluid at $37^{\circ} \mathrm{C}$ for $15 \mathrm{~min}$. The Rhodamine 123 working fluid was then removed, fresh PBS was added, and detection was performed using BD FACS Aria II flow cytometry with an excitation wavelength of $488 \mathrm{~nm}$, an emission wavelength of $525 \mathrm{~nm}$ and the channel of FITC. Finally, the results of flow cytometry were analyzed using Flowjo 10.1 software. All the above data are presented as the mean of at least three independent experimental repeats.

Tetramethylrhodamine methyl ester staining (JC-1; cat. no. KGA602; Nanjing KeyGen Biotech Co., Ltd.) were analyzed in the above three groups following incubation with $\mathrm{H}_{2} \mathrm{O}_{2}$ for $4 \mathrm{~h}$. Following treatment, the cells from each group were washed with PBS three times, harvested with $0.25 \%$ trypsin, and centrifuged at $400 \mathrm{x}$ g for $5 \mathrm{~min}$ at room temperature. The supernatant was discarded, and the cells was incubated with JC-1 working fluid at $37^{\circ} \mathrm{C}$ for $15 \mathrm{~min}$. Then JC-1 working fluid was then removed and fresh PBS was added. The analysis of JC-1 was detected with the channel of BD FACS Aria II flow cytometry via P-phycoerythrin and analyzed using Flowjo 10.1 
software. All the above data are presented as the mean of at least three independent experimental repeats.

Mitochondrial apoptogenic factors. The protein levels of cytochrome $c$ oxidase (cyto-C) and apoptosis-inducing factor (AIF) from cytosolic fractions were detected in the three experimental groups by western blotting. The cells were collected and lysed by RIPA buffer for $15 \mathrm{~min}$ and centrifuged at $15,000 \mathrm{x} \mathrm{g}$ for $30 \mathrm{~min}$ at $4^{\circ} \mathrm{C}$. The protein concentrations were analyzed using a NanoDrop instrument, and $40 \mu \mathrm{g}$ protein from each sample were run on $10 \%$ salt-polyacrylamide gel electrophoresis gels, and then transferred onto polyvinylidene fluoride membranes. Following blocking with $5 \%$ nonfat dry milk, the membranes were incubated overnight at $4^{\circ} \mathrm{C}$ with following primary mouse monoclonal antibodies: Anti-cyto-C (cat. no. AC908; Beyotime Institute of Biotechnology, Haimen, China], anti-AIF (cat. no. AB32516; Abcam, Cambridge, UK) or anti-glyceraldehyde-3-phosphate dehydrogenase (GAPDH; cat. no. AB181602; Abcam) at a dilution of 1:500. The membranes were washed and incubated in a 1:1,000 dilution of goat anti-mouse/rabbit HRP (cat. no. 115-035-003/111-035-003; Jackson ImmunoResearch Laboratories, Inc., West Grove, PA, USA) for $1 \mathrm{~h}$ at room temperature. The membranes were then washed and visualized using Pierce ${ }^{\mathrm{TM}}$ ECL western blotting substrate (Thermo Fisher Scientific, Inc.) followed by exposure to Tanon 5200 (Tanon Science and Technology Co., Ltd.). Anti-cyto-C, anti-AIF and GAPDH were detected as bands of approximately 15, 67 and $36 \mathrm{kDa}$, respectively. The data were normalized to the GAPDH content of the same sample and analyzed using Image J v1.8.0 (National Institutes of Health, Bethesda, MD, USA). Similar to the above methods, the levels of cyto-C and AIF from mitochondrial fractions were also analyzed in the aforementioned three groups using western blotting following incubation with $\mathrm{H}_{2} \mathrm{O}_{2}$ for $24 \mathrm{~h}$. The extracted proteins were incubated with the following primary mouse monoclonal antibodies: A 1:1,000 dilution of anti-cyto-C, anti-AIF or anti-cyclooxygenase-4 (COX-4; cat. no. AB33958; Abcam) for $12 \mathrm{~h}$ at $4^{\circ} \mathrm{C}$, followed by incubation in a 1:1,000 dilution of goat anti-mouse/rabbit HRP (Jackson ImmunoResearch Laboratories, Inc.) for $1 \mathrm{~h}$ at room temperature. Anti-cyto-C, anti-AIF and COX-4 were detected as bands of approximately 15,67 and $17 \mathrm{kDa}$, respectively. Bands were visualized according to the aforementioned procedure. Data were normalized to the content of COX-4 in the same sample and analyzed using Image $\mathbf{J}$ (National Institutes of Health). All the above data are presented as the mean of at least three independent experimental repeats.

Caspase proteins. The activation of caspase-3 and caspase- 9 was evaluated in the three experimental groups by western blot analysis at the time point of $24 \mathrm{~h}$. The extracted proteins were incubated with 1:1,000 dilutions of the following primary mouse monoclonal antibodies: Anti-caspase-3 (cat. no. AB2302; Abcam), anti-caspase-9 (cat. no. AB32539; Abcam) or anti-GAPDH for $12 \mathrm{~h}$ at $4^{\circ} \mathrm{C}$, followed by incubation in a 1:1,000 dilution of goat anti-mouse/rabbit HRP (Jackson ImmunoResearch Laboratories, Inc.) for $1 \mathrm{~h}$ at room temperature. Caspase-3 and caspase- 9 were detected as bands of approximately 17 and $46 \mathrm{kDa}$, respectively. Bands were visualized according to the aforementioned procedure. The data were normalized to the GAPDH content of the same sample and analyzed by ImageJ (National Institutes of Health). The above data are presented as the mean of at least three independent experimental repeats.

Animal models of injured skeletal muscle induced by $\mathrm{H}_{2} \mathrm{O}_{2}$. All procedures were approved by the Animal Ethics Committee at Shanghai East Hospital, Tongji University School of Medicine (Shanghai, China). In total, five Female BALB/C mice of 6-8-weeks of age (18-20 g) were purchased from Shanghai SLAC Laboratory Animal Co., Ltd. (Shanghai, China). Mice were kept in a controlled environment (temperature range, $22-24^{\circ} \mathrm{C}$; relative humidity, 40-60\%) with a $12 \mathrm{~h}$ light/dark cycle and had free access to food and water. Mice were fasted for at least $24 \mathrm{~h}$ before the experiment and anesthetized using isoflurane inhalation. Subsequently, $500 \mu \mathrm{M} \mathrm{H}_{2} \mathrm{O}_{2}$ was intramuscularly administered into the right hind leg. The left hind leg was intramuscularly administered with $500 \mu \mathrm{M} \mathrm{H}_{2} \mathrm{O}_{2}$, and the relevant group was pre-treated with $100 \mu \mathrm{M}$ baicalin for $1 \mathrm{~h}$. At 3 days post-treatment, the animal models were used for small animal PET imaging.

Small animal PET imaging. PET imaging was performed using a small animal PET scanner (Siemens Inveon). Briefly, the mice $(n=4)$ were injected with $3.7-5.55 \mathrm{MBq}(100-150 \mu \mathrm{Ci})$ of ${ }^{18} \mathrm{~F}-\mathrm{FDG}$ through the tail vein, and were anesthetized with $2 \%$ isoflurane for imaging experiments at $1 \mathrm{~h}$ p.i. The PET images were reconstructed and analyzed using the vendor-supplied software Inveon Research Workspace (Preclinical Solutions, Siemens Healthcare Molecular Imaging). Three-dimensional regions of interest (ROIs) were drawn over the organs and tissues on decay-corrected whole-body PET images. The results were divided by the injected dose, in order to obtain an image ROI-derived percent injected dose per gram of tissue (14).

Pathology. The BALB/C mice were sacrificed by cervical dislocation following anesthetization with isoflurane. Bilateral muscle lesions were separately fixed using $4 \%$ paraformaldehyde for $24 \mathrm{~h}$ and dehydrated using an ethanol series at room temperature. Following fixation and dehydration, the muscle samples were embedded in paraffin. Paraffin specimens were cut to a $5 \mu \mathrm{m}$ thickness and stained with hematoxylin and eosin $(\mathrm{H} \& \mathrm{E})$ for $1 \mathrm{~h}$ at room temperature. All stained samples were observed under a light microscope (Leica Microsystems $\mathrm{GmbH}$, Germany), and images were acquired under the same conditions and displayed at the same scale for comparison (magnification, x100).

Statistical analysis. The quantitative data are expressed as the mean \pm SD. Statistical analysis was performed using one-way ANOVA for the comparison of multiple groups and Student's t-test for two groups. A 95\% confidence level was selected, and $\mathrm{P}<0.05$ was considered to indicate a statistically significant difference.

\section{Results}

Baicalin increases cell viability of $\mathrm{H}_{2} \mathrm{O}_{2}$-stimulated c2c12 myoblasts. As illustrated in Fig. 1A, with increasing $\mathrm{H}_{2} \mathrm{O}_{2}$ 

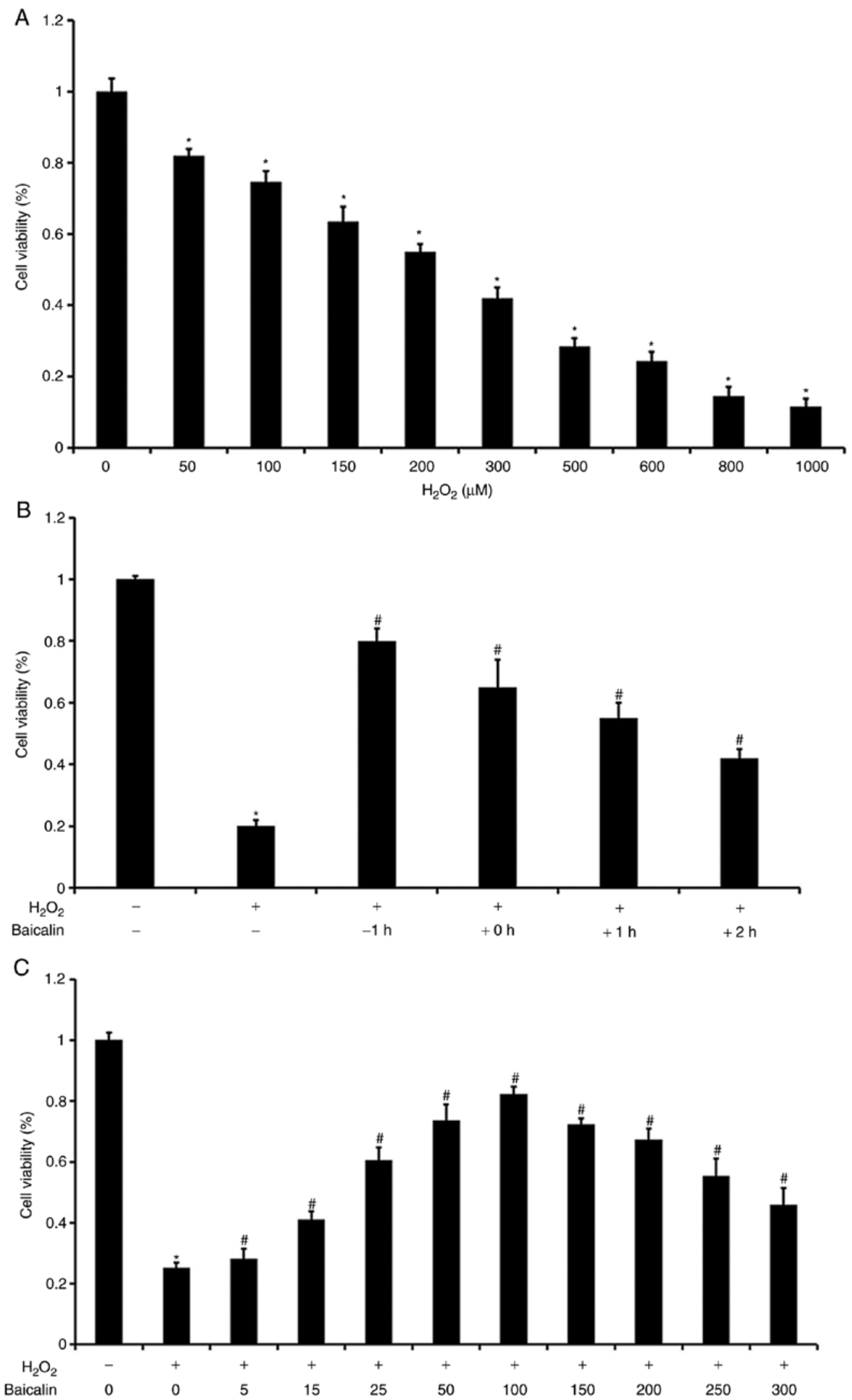

Figure 1. Effects on cell viability. (A) Cell viability of $\mathrm{C} 2 \mathrm{C} 12$ myoblasts treated with $\mathrm{H}_{2} \mathrm{O}_{2}$ at various concentrations. " $\mathrm{P}<0.05$, compared with the control group. (B) Effects of baicalin on the viability of $\mathrm{C} 2 \mathrm{C} 12$ myoblasts induced by $\mathrm{H}_{2} \mathrm{O}_{2}$ at different start time points. " $\mathrm{P}<0.05$, compared with the control group; ${ }^{*} \mathrm{P}<0.05$, compared with the $\mathrm{H}_{2} \mathrm{O}_{2}$ group. (C) Effects of pre-treatment with baicalin for $1 \mathrm{~h}$ on $\mathrm{C} 2 \mathrm{C} 12$ myoblasts at different concentrations. "P<0.05, compared with the control group; ${ }^{*} \mathrm{P}<0.05$, compared with the $\mathrm{H}_{2} \mathrm{O}_{2}$ group.

concentrations, the cell viability of the $\mathrm{C} 2 \mathrm{C} 12$ myoblasts was gradually decreased. The $\mathrm{H}_{2} \mathrm{O}_{2}$ concentration of $500 \mu \mathrm{M}$ was selected as an optimal dose for the subsequent experiments. As shown in Fig. 1B, it was observed that cell viability was 
A

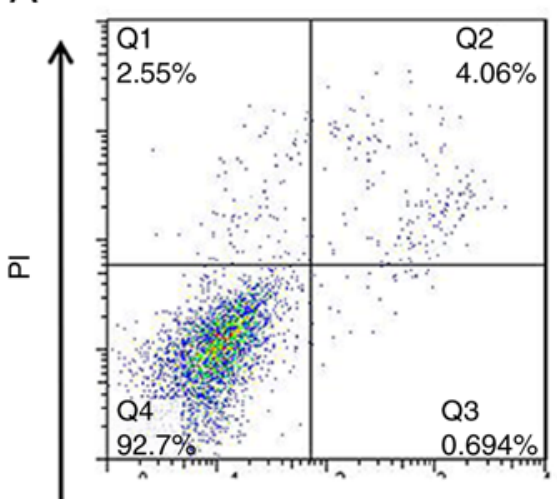

B
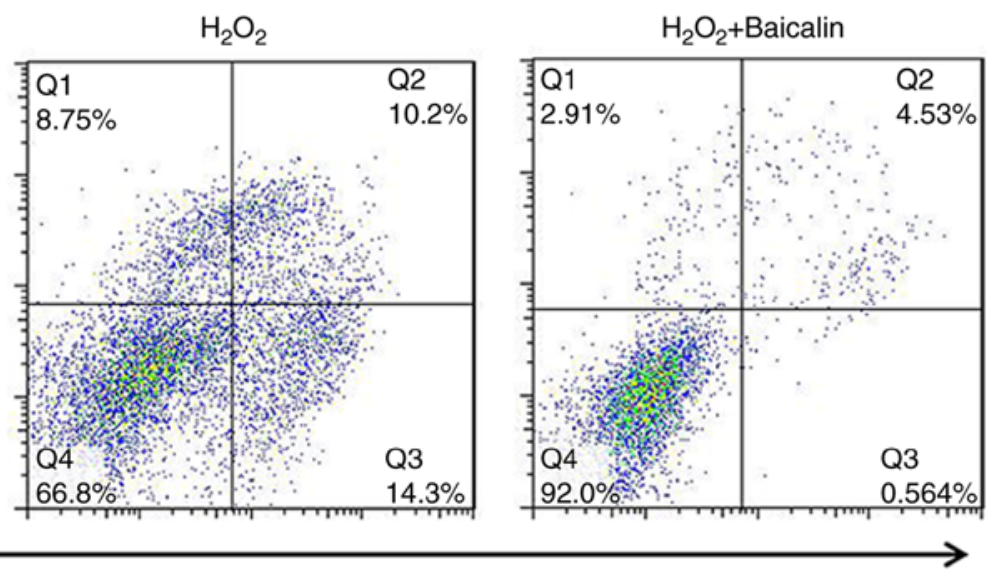

Annexin V

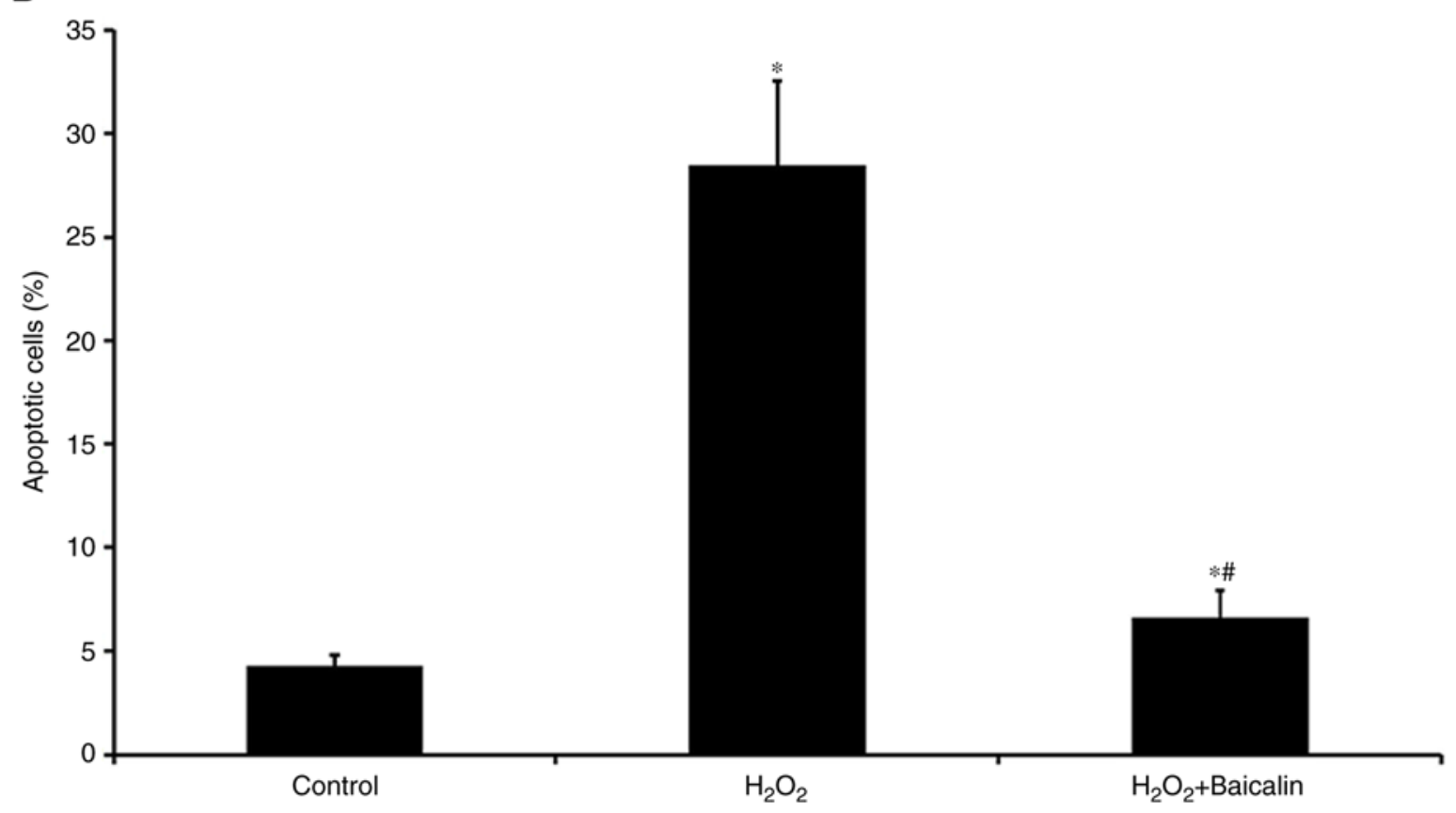

Figure 2. Analysis of apoptosis. (A) Flow cytometry of apoptosis of $\mathrm{C} 2 \mathrm{C} 12$ myoblasts in the control group, the group treated with $500 \mu \mathrm{M} \mathrm{H}_{2} \mathrm{O}_{2}$, and the group incubated with $500 \mu \mathrm{M} \mathrm{H}_{2} \mathrm{O}_{2}$ that had been pre-treated with $100 \mu \mathrm{M}$ baicalin for $1 \mathrm{~h}$. (B) Apoptotic rates of $\mathrm{C} 2 \mathrm{C} 12$ myoblasts in the three groups. " $\mathrm{P}<0.05$, compared with the control group; ${ }^{\#} \mathrm{P}<0.05$, compared with the $\mathrm{H}_{2} \mathrm{O}_{2}$ group.

highest when the $\mathrm{C} 2 \mathrm{C} 12$ myoblasts under $\mathrm{H}_{2} \mathrm{O}_{2}$ exposure were pre-treated with baicalin for $1 \mathrm{~h}$. Cell viability subsequently decreased with a gradual trend when the $\mathrm{C} 2 \mathrm{C} 12$ myoblasts were treated with baicalin no earlier than the start of incubation with $\mathrm{H}_{2} \mathrm{O}_{2}$. As baicalin concentrations increased, $\mathrm{C} 2 \mathrm{C} 12$ myoblast viability was initially gradually elevated, and then decreased under co-treatment with $500 \mu \mathrm{M} \mathrm{H}_{2} \mathrm{O}_{2}$. Cell viability was highest when the baicalin concentration reached $100 \mu \mathrm{M}$ (Fig. 1C). Therefore, a baicalin concentration of $100 \mu \mathrm{M}$ was selected as the model dose for the subsequent experiments.

Baicalin inhibits $\mathrm{C} 2 \mathrm{Cl} 2$ myoblast apoptosis induced by $\mathrm{H}_{2} \mathrm{O}_{2}$. The Annexin V/PI staining analysis revealed that, compared with the group treated with $\mathrm{H}_{2} \mathrm{O}_{2}$ alone for $4 \mathrm{~h}$, the apoptosis of $\mathrm{C} 2 \mathrm{C} 12$ myoblasts was significantly decreased in the group that had been pre-treated with baicalin for $1 \mathrm{~h}$ at the 4-h time point (Fig. 2A and B), which suggested that baicalin significantly suppressed the apoptosis of $\mathrm{C} 2 \mathrm{C} 12$ myoblasts induced by $\mathrm{H}_{2} \mathrm{O}_{2}$.
Baicalin decreases oxidative activity in C2C12 myoblasts induced by $\mathrm{H}_{2} \mathrm{O}_{2}$. As a biomarker of oxidative stress, the ROS levels of $\mathrm{C} 2 \mathrm{C} 12$ myoblasts were increased following treatment with $\mathrm{H}_{2} \mathrm{O}_{2}$ for $4 \mathrm{~h}$, which were markedly reversed by pre-treatment with baicalin for $1 \mathrm{~h}$ (Fig. 3A and B). Similarly, pre-treatment with baicalin for $1 \mathrm{~h}$ effectively reversed the abnormal MDA levels in $\mathrm{C} 2 \mathrm{C} 12$ myoblasts exposed to $\mathrm{H}_{2} \mathrm{O}_{2}$ for $4 \mathrm{~h}$ (Fig. 3C).

Baicalin reverses mitochondrial dysfunction in C2C12 myoblasts induced by $\mathrm{H}_{2} \mathrm{O}_{2}$. Mitochondrial dysfunction was also observed in $\mathrm{C} 2 \mathrm{C} 12$ myoblasts following exposure to $\mathrm{H}_{2} \mathrm{O}_{2}$ for $4 \mathrm{~h}$, which was reflected by the loss of mitochondrial activity, determined by Rhodamine 123 staining (Fig. 4A and B), and the decrease in mitochondrial membrane potential $(\Delta \Psi \mathrm{m})$ determined via JC-1 staining (Fig. 4C and D). However, as shown in Fig. 4, pre-treatment with baicalin for $1 \mathrm{~h}$ noticeably reversed the aforementioned effects and protected mitochondrial function. 
A

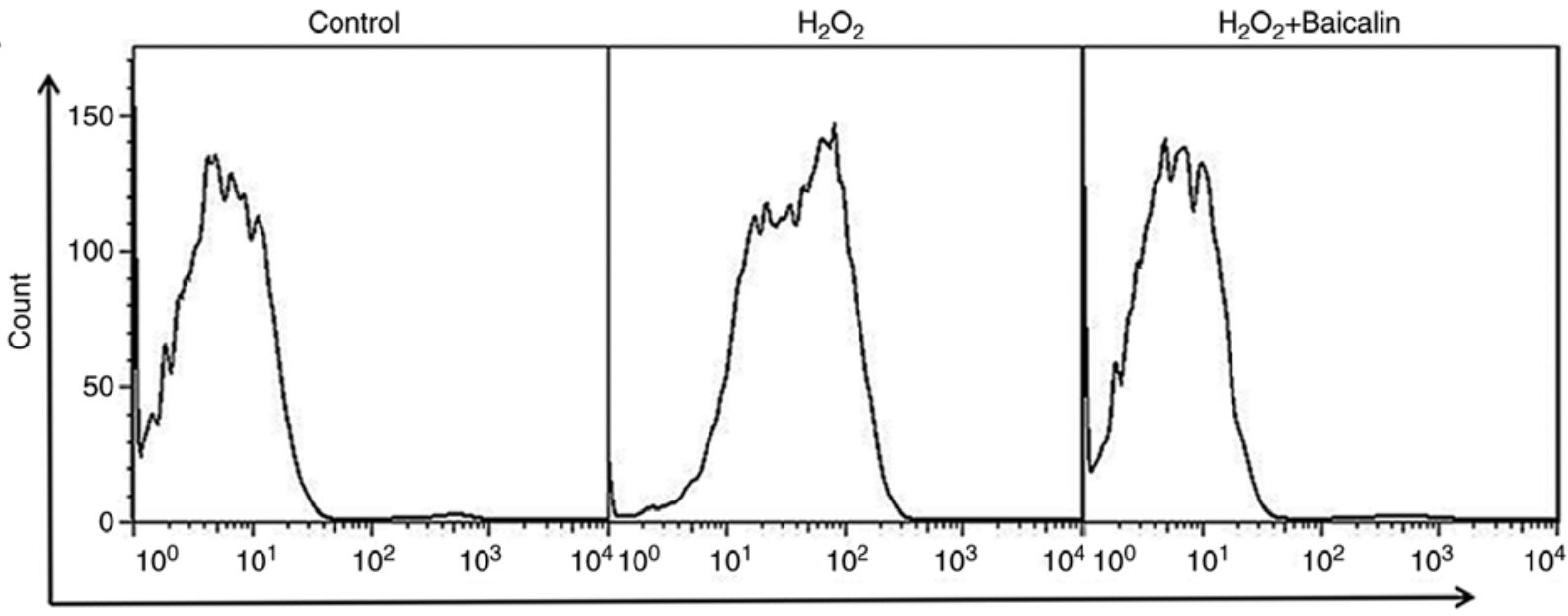

FITC-A

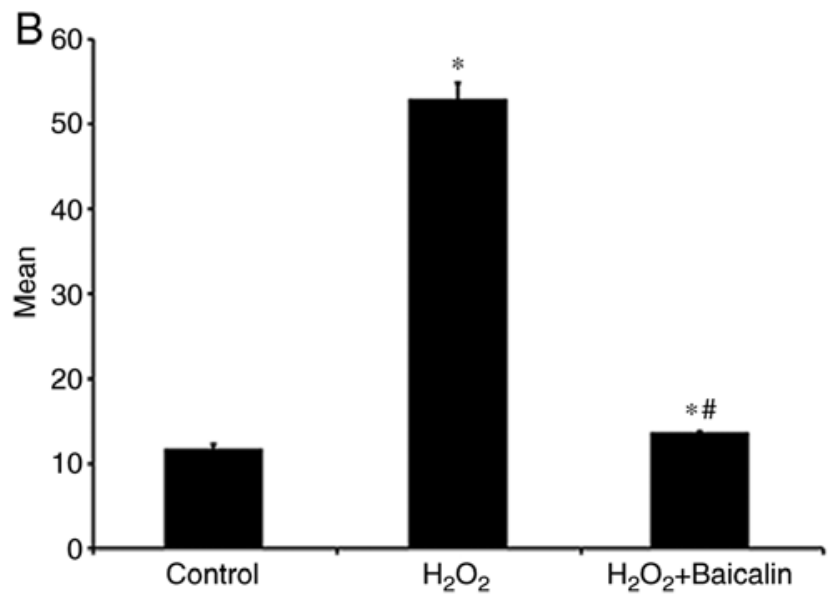

$\mathrm{C}$

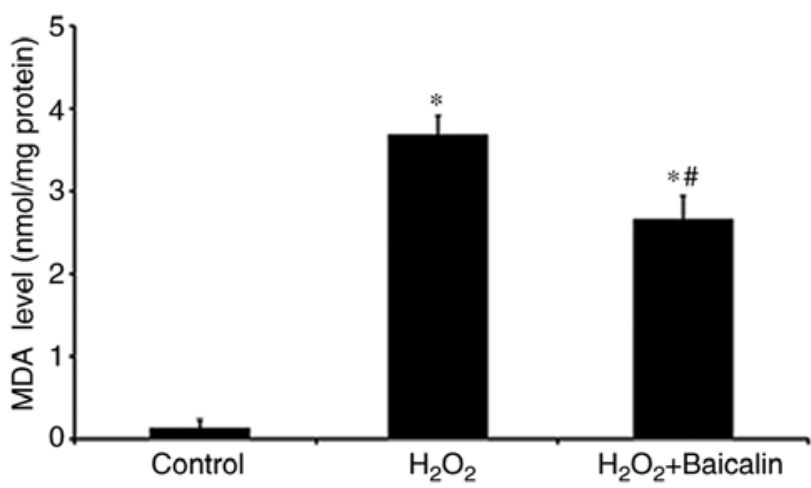

Figure 3. Levels of ROS and MDA. (A) Flow cytometry of ROS levels of $\mathrm{C} 2 \mathrm{C} 12$ myoblasts in the control group, the group treated with $500 \mu \mathrm{M} \mathrm{H}_{2} \mathrm{O}_{2}$, and the group incubated with $500 \mu \mathrm{M} \mathrm{H}_{2} \mathrm{O}_{2}$ plus $1 \mathrm{~h}$ pre-treatment with $100 \mu \mathrm{M}$ baicalin. (B) Quantification analysis of the results of flow cytometry for ROS. "P $<0.05$, compared with the control group; ${ }^{\prime} \mathrm{P}<0.05$, compared with the $\mathrm{H}_{2} \mathrm{O}_{2}$ group. (C) MDA levels of $\mathrm{C} 2 \mathrm{C} 12$ myoblasts in the three groups. "P $\mathrm{P}<0.05$, compared with the control group; ${ }^{~} \mathrm{P}<0.05$, compared with the $\mathrm{H}_{2} \mathrm{O}_{2}$ group. ROS, reactive oxygen species; MDA, malondialdehyde; FITC, fluorescein isothiocyanate.

Baicalin inhibits the release of mitochondrial apoptogenic factors induced by $\mathrm{H}_{2} \mathrm{O}_{2}$. The levels of cyto-C and AIF from cytosolic fractions were identified following the treatment of $\mathrm{C} 2 \mathrm{C} 12$ myoblasts with $\mathrm{H}_{2} \mathrm{O}_{2}$ for $24 \mathrm{~h}$, and these were marginally lower than those in the normal control (Fig. 5A). Pre-treatment with baicalin was observed to marginally upregulate the expression of cyto-C and AIF (Fig. 5A). This effect was corroborated by the quantification of the western blotting results, which are illustrated in Fig. 5B. The levels of cyto-C and AIF from mitochondrial fractions were also identified, and these were markedly lower than those in the normal control group (Fig. 5C). In addition, pre-treatment with baicalin significantly upregulated the levels of cyto-C and AIF (Fig. 5C). The quantification results of western blotting are presented in Fig. 5D.

Baicalin inhibits the activation of caspases in C2C12 myoblasts induced by $\mathrm{H}_{2} \mathrm{O}_{2}$. As presented in Fig. 6A, the protein expression levels of the caspase-3 and caspase- 9 were identified following the incubation of $\mathrm{C} 2 \mathrm{C} 12$ myoblasts with $500 \mu \mathrm{M} \mathrm{H}_{2} \mathrm{O}_{2}$ for $24 \mathrm{~h}$, which were markedly higher than those in the normal control group. Pre-treatment with baicalin significantly downregulated the expression of caspase- 3 and caspase- 9 , as shown from the quantification of western blotting results in Fig. $6 \mathrm{~B}(\mathrm{P}<0.05)$.
Small animal PET imaging of injured skeletal muscle. As illustrated in Fig. 7A, a representative coronal small animal ${ }^{18} \mathrm{~F}$-FDG PET image of an animal model of skeletal muscle injury induced by $\mathrm{H}_{2} \mathrm{O}_{2}$ is presented. The radioactivity uptake in the muscle lesion of the right leg was observed at $1 \mathrm{~h}$ p.i. However, there was no obvious FDG accumulation in the left leg lesion. Further quantification analysis demonstrated that the radioactivity uptake by the right and left muscle lesions were $3.20 \pm 0.52 \% \mathrm{ID} / \mathrm{g}$ and $1.09 \pm 0.22 \% \mathrm{ID} / \mathrm{g}$, respectively, and the ratio of right-to-left lesion was $2.94 \pm 0.25$ (Fig. 7B). In addition, the physiological radioactivity accumulation of normal muscle tissues was observed. In the other examined normal organs and tissues, including the brain, lung, heart, liver and kidneys, relatively low radioactivity accumulation was also observed, and the majority were $<2 \% \mathrm{ID} / \mathrm{g}$.

Pathological results. The H\&E staining revealed that the muscle tissues of the right leg were injured and infiltrated with masses of inflammatory cells following the induction of $\mathrm{H}_{2} \mathrm{O}_{2}$ (Fig. 8A, x100 magnification). The muscle tissues of the left leg exhibited a lesser degree of injury and less inflammatory cell infiltration following pre-treatment with baicalin for $1 \mathrm{~h}$ (Fig. 8B, x100 magnification). 

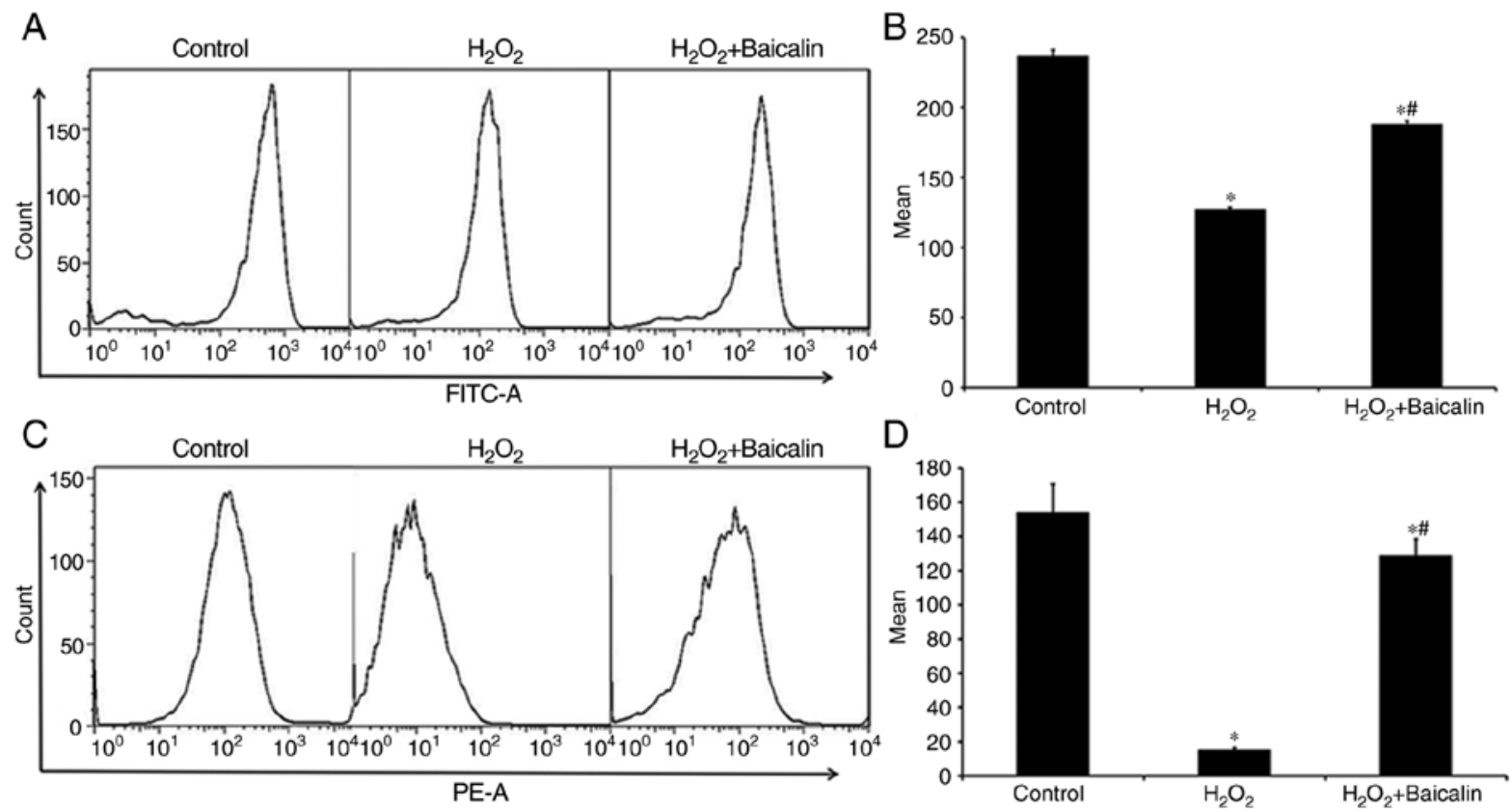

Figure 4. Effects on mitochondria. (A) Flow cytometry of mitochondrial activity (Rhodamine 123 staining) of $\mathrm{C} 2 \mathrm{C} 12$ myoblasts in the control group, the group treated with $500 \mu \mathrm{M} \mathrm{H}_{2} \mathrm{O}_{2}$, and the group incubated with $500 \mu \mathrm{M} \mathrm{H}_{2} \mathrm{O}_{2}$ that had been pre-treated with $100 \mu \mathrm{M}$ baicalin for $1 \mathrm{~h}$. (B) Quantification results of flow cytometry for Rhodamine 123 staining. " $\mathrm{P}<0.05$, compared with the control group; ${ }^{*} \mathrm{P}<0.05$, compared with the $\mathrm{H}_{2} \mathrm{O}_{2}$ group. (C) Flow cytometry of mitochondrial membrane potential (JC-1 staining) of $\mathrm{C} 2 \mathrm{C} 12$ myoblasts in the three aforementioned groups. (D) Quantification results of flow cytometry for JC-1 staining. " $\mathrm{P}<0.05$, compared with the control group; ${ }^{\mathrm{P}}<0.05$, compared with the $\mathrm{H}_{2} \mathrm{O}_{2}$ group. FITC, fluorescein isothiocyanate; $\mathrm{PE}$, phycoerythrin.

A

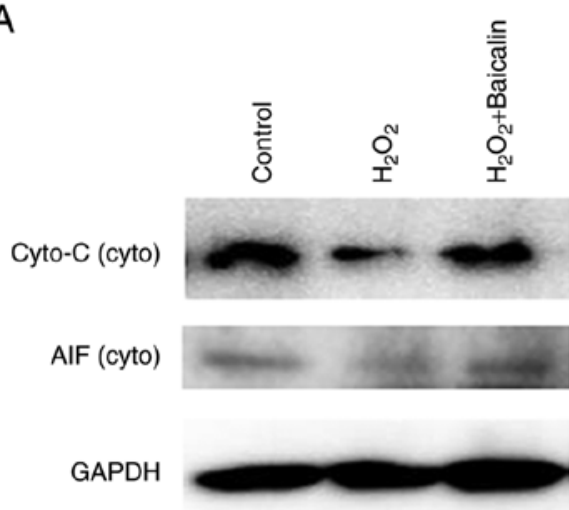

C

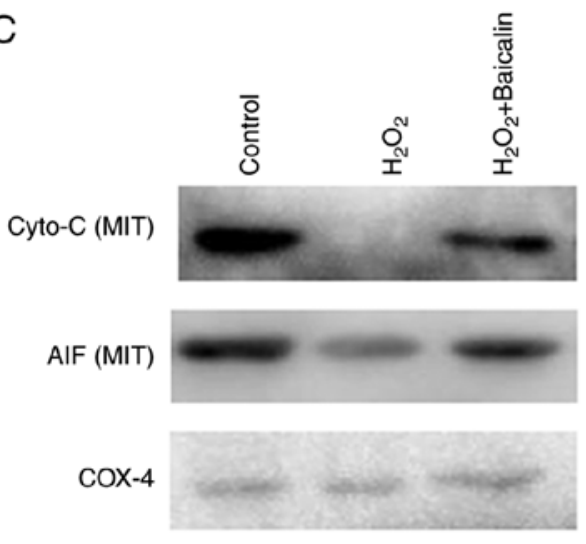

B

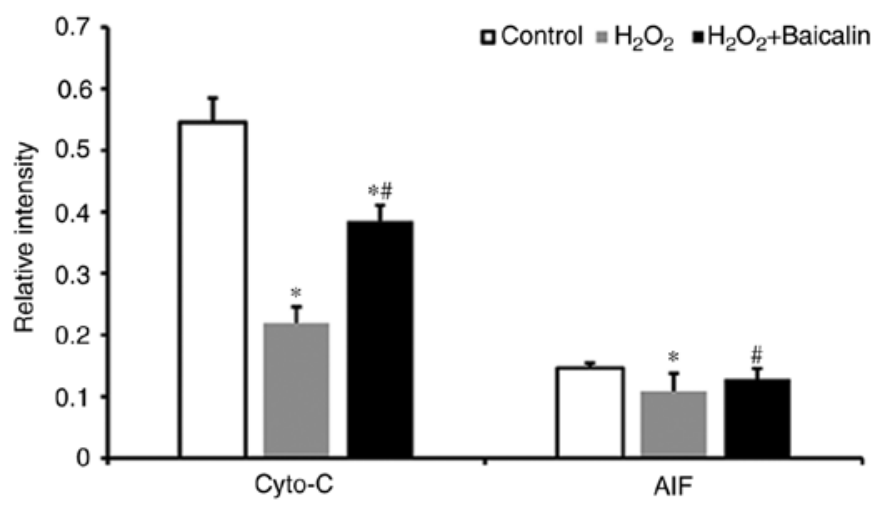

D

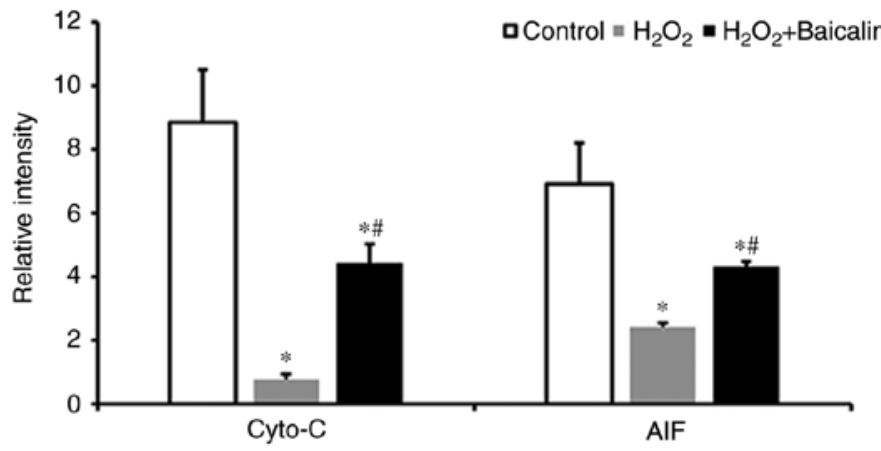

Figure 5. Levels of cyto-C and AIF. (A) Western blot of cyto-C and AIF from cytosolic fractions of $\mathrm{C} 2 \mathrm{C} 12$ myoblasts in the control group, the group treated with $500 \mu \mathrm{M} \mathrm{H}_{2} \mathrm{O}_{2}$, and the group incubated with $500 \mu \mathrm{M} \mathrm{H}_{2} \mathrm{O}_{2}$ that had been pre-treated with $100 \mu \mathrm{M}$ baicalin for $1 \mathrm{~h}$. (B) Quantification of the western blotting results of cyto-C and AIF levels from cytosolic fractions. ${ }^{*} \mathrm{P}<0.05$, compared with the control group; ${ }^{\prime \prime} \mathrm{P}<0.05$, compared with the $\mathrm{H}_{2} \mathrm{O}_{2}$ group. $(\mathrm{C}) \mathrm{Western}$ blot of cyto-C and AIF from mitochondrial fractions of $\mathrm{C} 2 \mathrm{C} 12$ myoblasts in the three aforementioned groups. (D) Quantification of western blotting results of cyto-C and AIF levels from mitochondrial fractions. ${ }^{*} \mathrm{P}<0.05$, compared with the control group; ${ }^{*} \mathrm{P}<0.05$, compared with the $\mathrm{H}_{2} \mathrm{O}_{2}$ group. cyto-C, cytochrome $c$ oxidase; AIF, apoptosis-inducing factor; GAPDH, glyceraldehyde-3-phosphate dehydrogenase; cyto, cytosolic; MIT, mitochondrial. 

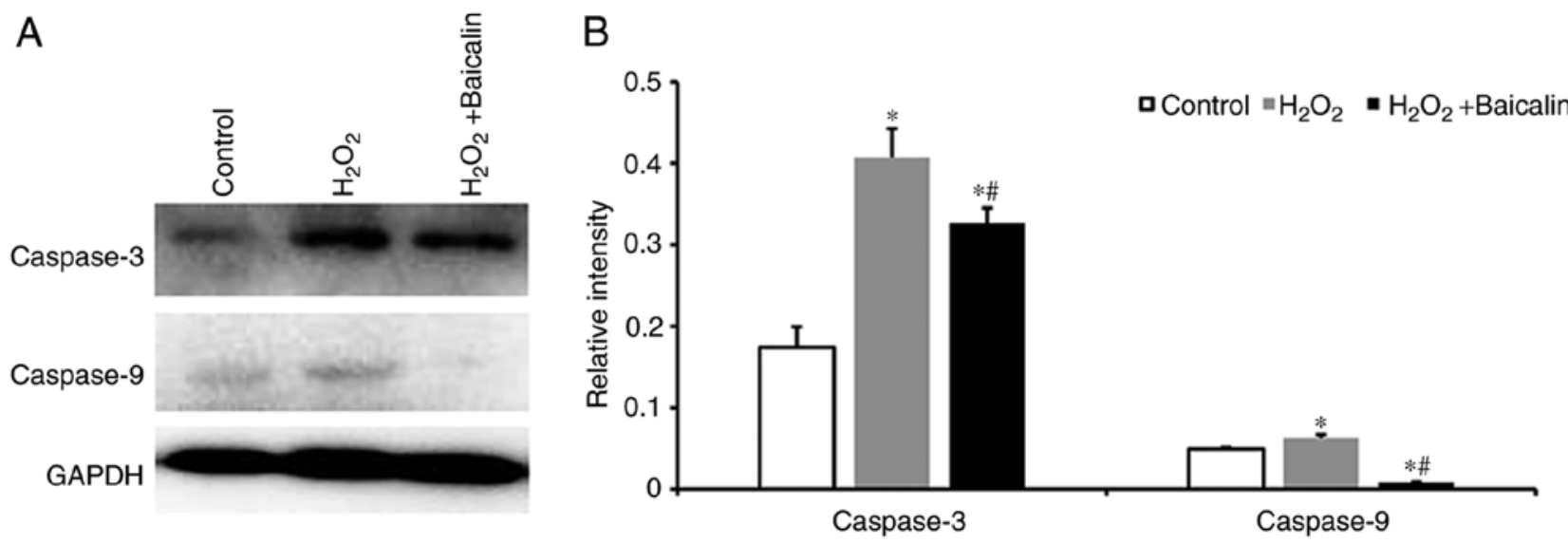

Figure 6. Effects on caspase expression. (A) Western blotting of the expression of caspase-3 and caspase- 9 of $\mathrm{C} 2 \mathrm{C} 12$ myoblasts in the control group, the group treated with $500 \mu \mathrm{M} \mathrm{H}_{2} \mathrm{O}_{2}$, and the group incubated with $500 \mu \mathrm{M} \mathrm{H}_{2} \mathrm{O}_{2}$ that has been pre-treated with $100 \mu \mathrm{M}$ baicalin for $1 \mathrm{~h}$. (B) Quantification of western blotting results. ${ }^{\mathrm{P}}<0.05$, compared with the control group; ${ }^{*} \mathrm{P}<0.05$, compared with the $\mathrm{H}_{2} \mathrm{O}_{2}$ group.
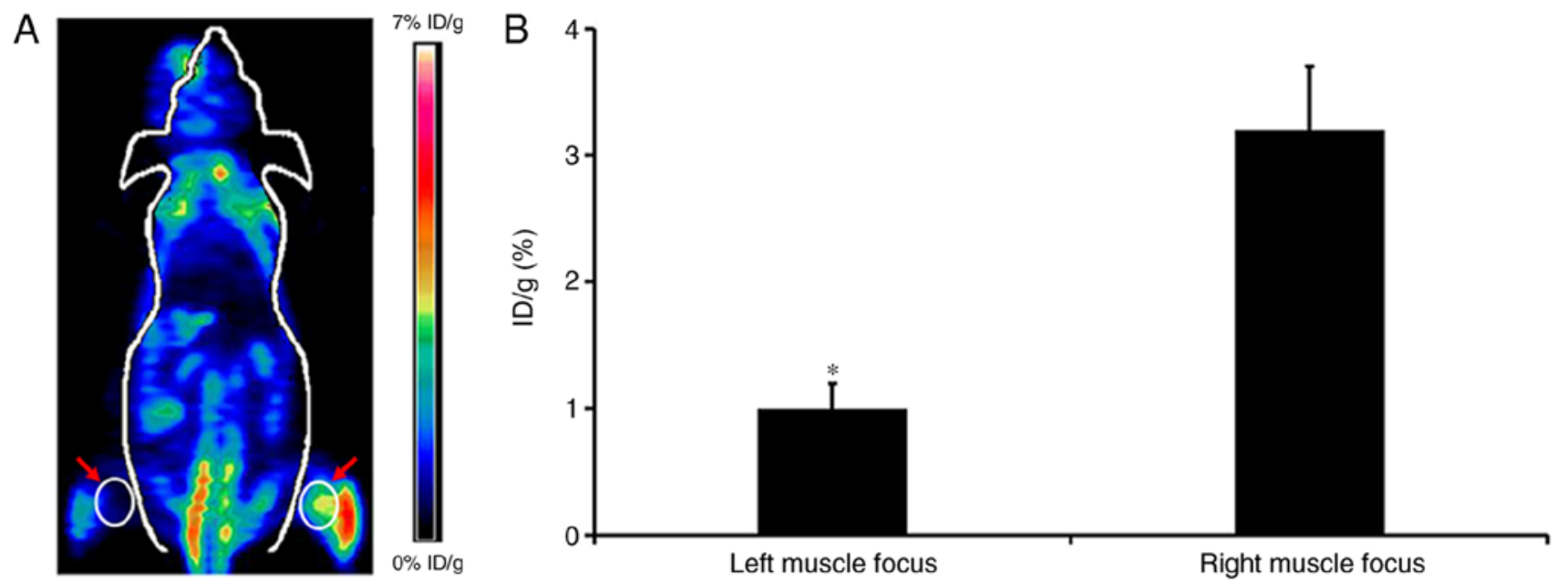

Figure 7. ${ }^{18}$ F-FDG PET imaging. (A) Coronal small animal PET image at $1 \mathrm{~h}$ following intravenous injection of ${ }^{18}$ F-FDG. (B) Small animal PET quantification analysis. ${ }^{2} \mathrm{P}<0.05$ vs. right muscle focus. ${ }^{18} \mathrm{~F}-\mathrm{FDG}, \beta-2-[18 \mathrm{~F}]$-fluoro-2-deoxy-D-glucose; PET, positron emission tomography.
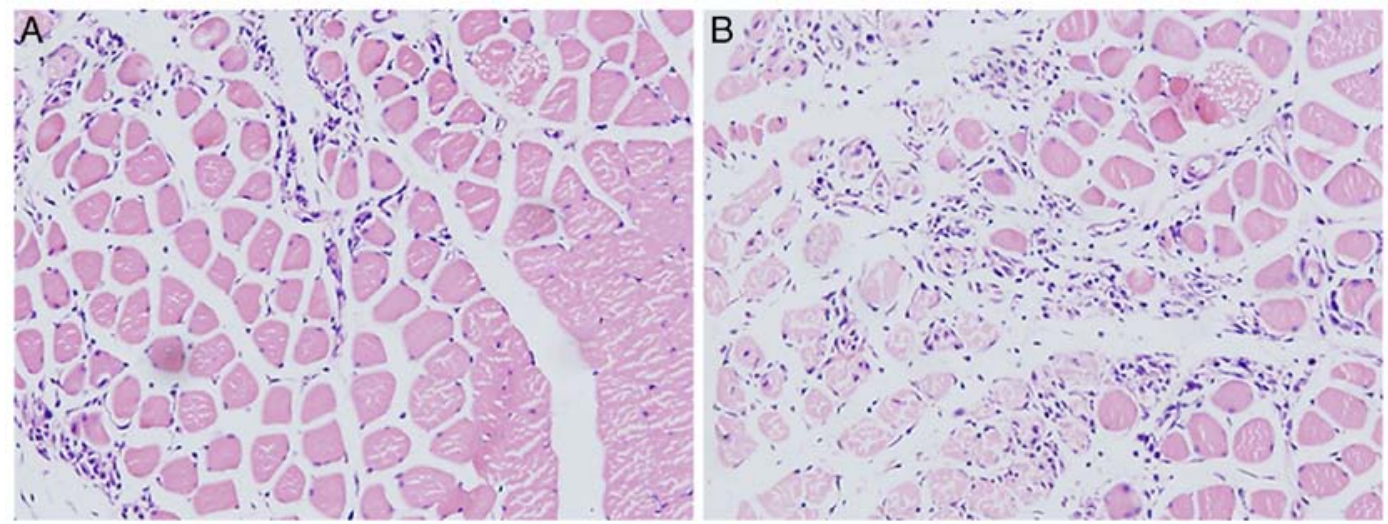

Figure 8. Pathological results. Pathological image of a (A) left leg muscle focus, which had been injected with $500 \mu \mathrm{M} \mathrm{H}_{2} \mathrm{O}_{2}$ following $1 \mathrm{~h}$ pre-treatment with $100 \mu \mathrm{M}$ baicalin, and a (B) right leg muscle focus injected with $500 \mu \mathrm{M} \mathrm{H}_{2} \mathrm{O}_{2}$ only (magnification, $\mathrm{x} 100$ ).

\section{Discussion}

As a flavonoid glycoside extracted from Scutellariabaicalensis, a type of traditional Chinese medicine, baicalin has been reported to possess significant anti-inflammatory and anti-apoptotic properties, and is widely used in the treatment of injuries and inflammatory diseases (7-12). In addition, the results of our previous study confirmed the protective effects 
of treatment with baicalin on $\mathrm{H}_{2} \mathrm{O}_{2}$-induced apoptosis in endplate chondrocytes (13). Therefore, the aim of the present study was focused on the protective effects of baicalin on $\mathrm{H}_{2} \mathrm{O}_{2}$-stimulated $\mathrm{C} 2 \mathrm{C} 12$ myoblasts in vitro and animal models with skeletal muscle injury in vivo.

Initially, the present study confirmed the protective effects of baicalin on the viability of $\mathrm{C} 2 \mathrm{C} 12$ myoblasts using a CCK- 8 assay. $\mathrm{H}_{2} \mathrm{O}_{2}$ was observed to decrease the viability of the $\mathrm{C} 2 \mathrm{C} 12$ myoblasts, and the effects of $\mathrm{H}_{2} \mathrm{O}_{2}$ on $\mathrm{C} 2 \mathrm{C} 12$ myoblasts were dose-dependent. With increased $\mathrm{H}_{2} \mathrm{O}_{2}$ dose, the viability of the $\mathrm{C} 2 \mathrm{C} 12$ myoblasts was significantly decreased. The potential protective effects of baicalin against $\mathrm{H}_{2} \mathrm{O}_{2}$, with an obvious increase in cell viability, were observed using the CCK- 8 assay, with baicalin pre-treatment for $1 \mathrm{~h}$ exhibiting an optimal protective effect against the $\mathrm{H}_{2} \mathrm{O}_{2}$-induced loss of $\mathrm{C} 2 \mathrm{C} 12$ myoblasts. In addition, the results under different concentrations of baicalin pre-treatment were analyzed to identify an appropriate concentration with the most effective protective effect; the results revealed that $100 \mu \mathrm{M}$ baicalin had the highest efficacy, and was selected as a model dose for further in vitro and in vivo experiments.

The present study subsequently observed that pre-treatment with baicalin suppressed the activation of the apoptotic $\mathrm{C} 2 \mathrm{C} 12$ cell death pathway triggered by $\mathrm{H}_{2} \mathrm{O}_{2}$, which was similar to the results obtained in previous studies $(7,8,13)$. Decreased apoptosis was found to be associated with the suppression of $\mathrm{H}_{2} \mathrm{O}_{2}$-stimulated oxidative activity in $\mathrm{C} 2 \mathrm{C} 12$ myoblasts by baicalin, via effectively reducing the levels of ROS and MDA, which demonstrated that the protective effects of baicalin on $\mathrm{C} 2 \mathrm{C} 12$ myoblasts were associated with reduced oxidative stress (15-17). Mitochondrial dysfunction was also observed in $\mathrm{C} 2 \mathrm{C} 12$ myoblasts following exposure to $\mathrm{H}_{2} \mathrm{O}_{2}$, which was reflected by the loss of mitochondrial activity (Rhodamine 123 staining) and $\Delta \Psi \mathrm{m}$ (JC-1 staining). Baicalin also reversed the effect of $\mathrm{H}_{2} \mathrm{O}_{2}$ and preserved mitochondrial function. One of the important functions of the mitochondria is the regulation of apoptosis (18). The present study demonstrated that pre-treatment with baicalin significantly upregulated the expression levels of cyto-C and AIF from the cytosolic and mitochondrial fractions of $\mathrm{C} 2 \mathrm{C} 12$ myoblasts exposed to $\mathrm{H}_{2} \mathrm{O}_{2}$. In addition, caspase- 3 and caspase- 9 are commonly accepted indicators of apoptosis $(15,19)$, and pre-treatment with baicalin in the present study downregulated the activities of caspase-3 and caspase- 9 in the $\mathrm{C} 2 \mathrm{C} 12$ myoblasts induced by $\mathrm{H}_{2} \mathrm{O}_{2}$ stimulation. In summary, these pathophysiological processes demonstrated the protective effects of baicalin on $\mathrm{C} 2 \mathrm{C} 12$ myoblasts via inhibiting activation of the intrinsic apoptotic pathway, which was consistent with previously reported findings $(13,18,20)$.

The present study further investigated the potential protective role of baicalin in vivo on the basis of animal models of skeletal muscle injury. Baicalin was pre-administered intra-muscularly $1 \mathrm{~h}$ prior to $\mathrm{H}_{2} \mathrm{O}_{2}$ injection at the same position, with the contralateral muscle receiving $\mathrm{H}_{2} \mathrm{O}_{2}$ injection only. At present, numerous imaging agents have been used for inflammation PET imaging, including ${ }^{18} \mathrm{~F}-\mathrm{FDG},{ }^{68} \mathrm{Ga}$-Citrate and ${ }^{64} \mathrm{CuCl}_{2}$ (21-27). ${ }^{18} \mathrm{~F}-\mathrm{FDG}$ is produced by the cyclotron, which is easy and convenient to access, and has been widely used in a clinical setting (27). Therefore, in the present study, the animal models of skeletal muscle injury underwent small animal ${ }^{18} \mathrm{~F}$-FDG PET imaging, which revealed that baicalin decreased $\sim 65.9 \%$ of the FDG accumulation in the skeletal muscle injury induced by $\mathrm{H}_{2} \mathrm{O}_{2}$. In addition, baicalin inhibited and prevented the physiological uptake in normal leg muscle. These pathological findings confirmed the protective effect of baicalin on skeletal muscle injury. Therefore, baicalin was confirmed to effectively protect against the skeletal muscle injury induced by $\mathrm{H}_{2} \mathrm{O}_{2}$ in vivo.

However, the primary limitation of the present study was the mechanism of baicalin-mediated protection against apoptosis and inflammation, which was not fully elucidated and may be associated with molecular signaling, including nuclear factor erythroid 2-related factor 2 signaling, AMP-activated protein kinase, peroxisome proliferator-activated receptor- $\gamma$, proteasome, macrophages and notch signaling. These possibilities were not examined in the present study, and warrant further investigation (28-32).

In conclusion, the results of the present study suggested that pre-treatment with baicalin has the potential to protect myoblasts from apoptosis via decreasing the production of ROS and MDA, preserving mitochondrial function and reversing caspase protein expression, which was further verified by small animal PET imaging and pathological analysis. These results indicate the potential benefits of baicalin for patients with skeletal muscle injury.

\section{Acknowledgements}

Not applicable.

\section{Funding}

This study was supported by the National Science Foundation for Young Scholars of China (grant no. 81601675 to YP).

\section{Availability of data and materials}

The datasets used and/or analyzed during the current study are available from the corresponding author on reasonable request.

\section{Authors' contributions}

ZL, YP and DS designed the study. YP, DS, WZ, XL and HW carried out the experiments and collected the data. ZL, YP and DS wrote and edited the manuscript.

\section{Ethics approval and consent to participate}

All procedures were approved by the Animal Ethics Committee at Shanghai East Hospital, Tongji University School of Medicine.

\section{Patient consent for publication}

Not applicable.

\section{Competing interests}

The authors declare that they have no competing interests. 


\section{References}

1. Urso ML: Anti-inflammatory interventions and skeletal muscle injury: Benefit or detriment. J Appl Physiol (1985) 115: 920-928, 2013 .

2. Bardouille C, Vullhorst D and Jockusch H: Expression of chloride channel 1 mRNA in cultured myogenic cells: A marker of myotube maturation. FEBS Lett 396: 177-180, 1996.

3. Smith C, Kruger MJ, Smith RM and Myburgh KH: The inflammatory response to skeletal muscle injury: Illuminating complexities. Sports Med 38: 947-969, 2008.

4. Arnold L, Henry A, Poron F, Baba-Amer Y, van Rooijen N, Plonquet A, Gherardi RK and Chazaud B: Inflammatory monocytes recruited after skeletal muscle injury switch into antiinflammatory macrophages to support myogenesis. J Exp Med 204: 1057-1069, 2007.

5. Joulia D, Bernardi H, Garandel V, Rabenoelina F, Vernus B and Cabello G: Mechanisms involved in the inhibition of myoblast proliferation and differentiation by myostatin. Exp Cell Res 286: 263-275, 2003.

6. Steffens AA, Hong GM and Bain LJ: Sodium arsenite delays the differentiation of $\mathrm{C} 2 \mathrm{C} 12$ mouse myoblast cells and alters methylation patterns on the transcription factor myogenin. Toxicol Appl Pharmacol 250: 154-161, 2011.

7. Lin M, Li L, Zhang Y, Zheng L, Xu M, Rong R and Zhu T: Baicalin ameliorates $\mathrm{H} 2 \mathrm{O} 2$ induced cytotoxicity in HK-2 cells through the inhibition of ER stress and the activation of Nrf2 signaling. Int J Mol Sci 15: 12507-12522, 2014.

8. Lin M, Li L, Li L, Pokhrel G, Qi G, Rong R and Zhu T: The protective effect of baicalin against renal ischemia-reperfusion injury through inhibition of inflammation and apoptosis. BMC Complement Alternat Med 14: 19, 2014.

9. Cao Y, Mao X, Sun C, Zheng P, Gao J, Wang X, Min D, Sun H, Xie N and Cai J: Baicalin attenuates global cerebral ischemia/reperfusion injury in gerbils via anti-oxidative and anti-apoptotic pathways. Brain Res Bull 85: 396-402, 2011.

10. Zhu J, Wang J, Sheng Y, Zou Y, Bo L, Wang F, Lou J, Fan X, Bao R, Wu Y, et al: Baicalin improves survival in a murine model of polymicrobial sepsis via suppressing inflammatory response and lymphocyte apoptosis. PLoS One 7: e35523, 2012.

11. Xiping Z, Guanghua F, Jinxian H, Weihong W, Rujun X, Wei Z, Jing Y, Qijun Y, Meijuan Y, Qing W and Lini F: Baicalin protects thymus of rats with severe acute pancreatitis. Inflammation 33: 157-165, 2010.

12. Chen $X$, Nishida $H$ and Konishi T: Baicalin promoted the repair of DNA single strand breakage caused by $\mathrm{H}_{2} \mathrm{O}_{2}$ in cultured NIH3T3 fibroblasts. Biol Pharm Bull 26: 282-284, 2003.

13. Pan Y, Chen D, Lu Q, Liu L, Li X and Li Z: Baicalin prevents the apoptosis of endplate chondrocytes by inhibiting the oxidative stress induced by H2O2. Mol Med Rep 16: 2985-2991, 2017.

14. Jiang L, Kimura RH, Miao Z, Silverman AP, Ren G, Liu H, Li P, Gambhir SS, Cochran JR and Cheng Z: Evaluation of a (64) $\mathrm{Cu}$-labeled cystine-knot peptide based on agouti-related protein for PET of tumors expressing alphavbeta3 integrin. J Nucl Med 51: 251-258, 2010.

15. Mao CY, Lu HB, Kong N, Li JY, Liu M, Yang CY and Yang P: Levocarnitine protects $\mathrm{H} 9 \mathrm{c} 2$ rat cardiomyocytes from $\mathrm{H}_{2} \mathrm{O}_{2}$-induced mitochondrial dysfunction and apoptosis. Int $\mathrm{J}$ Med Sci 11: 1107-1115, 2014

16. Chen S, Tang Y, Qian Y, Chen R, Zhang L, Wo L and Chai H: Allicin prevents $\mathrm{H}_{2} \mathrm{O}_{2}$-induced apoptosis of HUVECs by inhibiting an oxidative stress pathway. BMC Complement Altern Med 14: 321, 2014.
17. Hsu PC and Guo YL: Antioxidant nutrients and lead toxicity. Toxicology 180: 33-44, 2002.

18. Yu CY, Chiang RL, Chang TH, Liao CL and Lin YL: The interferon stimulator mitochondrial antiviral signaling protein facilitates cell death by disrupting the mitochondrial membrane potential and by activating caspases. J Virol 84: 2421-2431, 2010.

19. Shen J, Zhu Y, Huang K, Jiang H, Shi C, Xiong X, Zhan R and Pan J: Buyang huanwu decoction attenuates $\mathrm{H} 2 \mathrm{O} 2$-induced apoptosis by inhibiting reactive oxygen species-mediated mitochondrial dysfunction pathway in human umbilical vein endothelial cells. BMC Complement Alternat Med 16: 154, 2016.

20. Xue HY, Niu DY, Gao GZ, Lin QY, Jin LJ and Xu YP: Aucubin modulates Bcl-2 family proteins expression and inhibits caspases cascade in $\mathrm{H}_{2} \mathrm{O}_{2}$-induced PC12 cells. Mol Biol Rep 38: 3561-3567, 2011.

21. Jiang L, Song D, Chen H, Zhang A, Wang H and Cheng Z: Pilot Study of ${ }^{64} \mathrm{CuCl}_{2}$ for PET Imaging of Inflammation. Molecules 23: pii: E502, 2018.

22. Xie F, Cai $\mathrm{H}$ and Peng F: ${ }^{64} \mathrm{CuCl}_{2}$ PET/CT imaging of mouse muscular injury induced by electroporation. Am J Nucl Med Mol Imaging 7: 33-39, 2017.

23. Kumar V and Boddeti DK: (68)Ga-radiopharmaceuticals for PET imaging of infection and inflammation. Recent Results Cancer Res 194: 189-219, 2013

24. Rudd JH, Myers KS, Bansilal S, Machac J, Pinto CA, Tong C, Rafique A, Hargeaves R, Farkouh M, Fuster V and Fayad ZA: Atherosclerosis inflammation imaging with $18 \mathrm{~F}-\mathrm{FDG}$ PET: Carotid, iliac, and femoral uptake reproducibility, quantification methods, and recommendations. J Nucl Med 49: 871-878, 2008.

25. Pellegrino D, Bonab AA, Dragotakes SC, Pitman JT, Mariani G and Carter EA: Inflammation and infection: Imaging properties of 18F-FDG-labeled white blood cells versus 18F-FDG. J Nucl Med 46: 1522-1530, 2005.

26. de Prost N, Tucci MR and Melo MF: Assessment of lung inflammation with 18F-FDG PET during acute lung injury. AJR Am J Roentgenol 195: 292-300, 2010.

27. Kobayashi $Y$, Ishii $K$, Oda K, Nariai T, Tanaka Y, Ishiwata $K$ and Numano F: Aortic wall inflammation due to Takayasu arteritis imaged with 18F-FDG PET coregistered with enhanced CT. J Nucl Med 46: 917-922, 2005.

28. Ma Y, Yang F, Wang Y, Du Z, Liu D, Guo H, Shen J and Peng H: $\mathrm{CaMKK} \beta$ is involved in AMP-activated protein kinase activation by baicalin in LKB1 deficient cell lines. PLoS One 7: e47900, 2012.

29. Lim HA, Lee EK, Kim JM, Park MH, Kim DH, Choi YJ, Ha YM, Yoon JH, Choi JS, Yu BP and Chung HY: PPAR $\gamma$ activation by baicalin suppresses NF- $\mathrm{BB}$-mediated inflammation in aged rat kidney. Biogerontology 13: 133-145, 2012.

30. Wu YX, Sato E, Kimura W and Miura N: Baicalin and scutellarin are proteasome inhibitors that specifically target chymotrypsin-like catalytic activity. Phytother Res 27: 1362-1367, 2013.

31. Liu LL, Gong LK, Wang H, Xiao Y, Wu XF, Zhang YH, Xue X, Qi XM and Ren J: Baicalin inhibits macrophage activation by lipopolysaccharide and protects mice from endotoxin shock. Biochem Pharmacol 75: 914-922, 2008.

32. Wang AM, Ku HH, Liang YC, Chen YC, Hwu YM and Yeh TS: The autonomous notch signal pathway is activated by baicalin and baicalein but is suppressed by niclosamide in K562 cells. J Cell Biochem 106: 682-692, 2009. 